\title{
Availability, Performance AND RELIABILITY EVALUATION FOR PV DISTRIBUTED GENERATION
}

\author{
Abdulrahman K. Al-Sefri ${ }^{1}$, Abdullah M. Al-Shaalan ${ }^{2}$, Abdulhameed A. \\ Al-Ohaly ${ }^{2}$ \\ ${ }^{1}$ Schneider Electric Company Riyadh, Kingdom of Saudi Arabia \\ ${ }^{2}$ Department of Electrical Engineering, King Saud University, Riyadh, \\ Kingdom of Saudi Arabia
}

\begin{abstract}
Nowadays, renewable energy resources play an important role in replacing conventional energy resources. Photovoltaic energy is considered to be promising renewable energy resources which grew rapidly in the past few years. The primary objective of this paper is to facilitate the increasing penetration levels of $P V$ systems in the electric distribution networks. The PV electrical model is presented and implemented on MATLAB to simulate the non-linear characteristics $I-V$ and $P-V$ curves. In addition, the reliability evaluation of distribution networks, including distributed generators of solar photovoltaic $(P V)$ with varying of output power capacity is also presented. The Monte Carlo simulation algorithm is applied to test the distribution famous networks RBTS Bus 2 as well as substation 7029 located near Riyadh city. The two distribution networks have been modified to include the PV's of distributed generators. The distributed generators contribute to supply a part of the load during normal mode and supply the entire load during component failure or failure of grid operation supply. The PV stochastic models have been used to simulate the randomness of these resources. The study shows that the implementation and integration of renewable resources as distributed generations have noticeably improved the reliability and service continuity of the distribution networks.
\end{abstract}

\section{KEYWORDS}

Reliability Evaluation, Photovoltaic System (PV), Distributed Generations, Monte Carlo Simulation.

\section{INTRODUCTION}

The electric power system has been used to generate, transmit and distribute power since the advent of electricity evolution and the foremost important objective of an electrical utility is to deliver economical, reliable, and quality power to its consumer. The electrical power network is extremely complex, a failure may result in loss of power to a large number of customers or sometimes catastrophic events such as blackouts and it is difficult to analyze the entire system at once. For this reason, the power system is divided into three functional zones such as generation facility, transmission facility and distribution facility to evaluate the reliability of the system. These functional zones in series can be considered as the hierarchical levels of the power system reliability studies as shown in figure 1 [1]. Hierarchical level I deals with the reliability evaluation of only generation system and the main indices analyzed in this study are loss of load 
Electrical Engineering: An International Journal (EEIJ) Vol.6, No.1/2, June 2019

expectation (LOLE), loss of energy expectation (LOEE), failure frequency and failure duration. Hierarchical level II is composed of generation and transmission facilities and it deals with the reliability evaluation of the both generation and transmission systems. Hierarchical level III includes all of the three functional zones and refers to as the complete electric power system. It deals with the reliability evaluation of the generation, transmission and distribution systems.

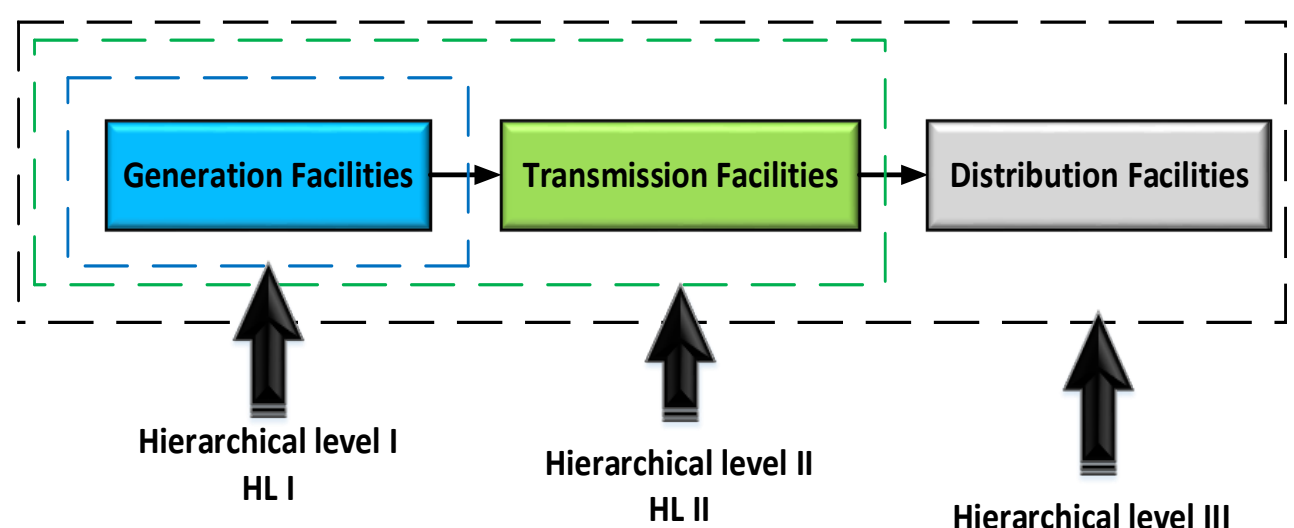

Figure 1. Functional zones and hierarchical levels of power system.

The conventional structure of electrical power systems has been developed mainly to become as following arrangement shown below in figure 2. The electric power is generated in large generating plants at a relatively small number of locations which will here be called central stations.

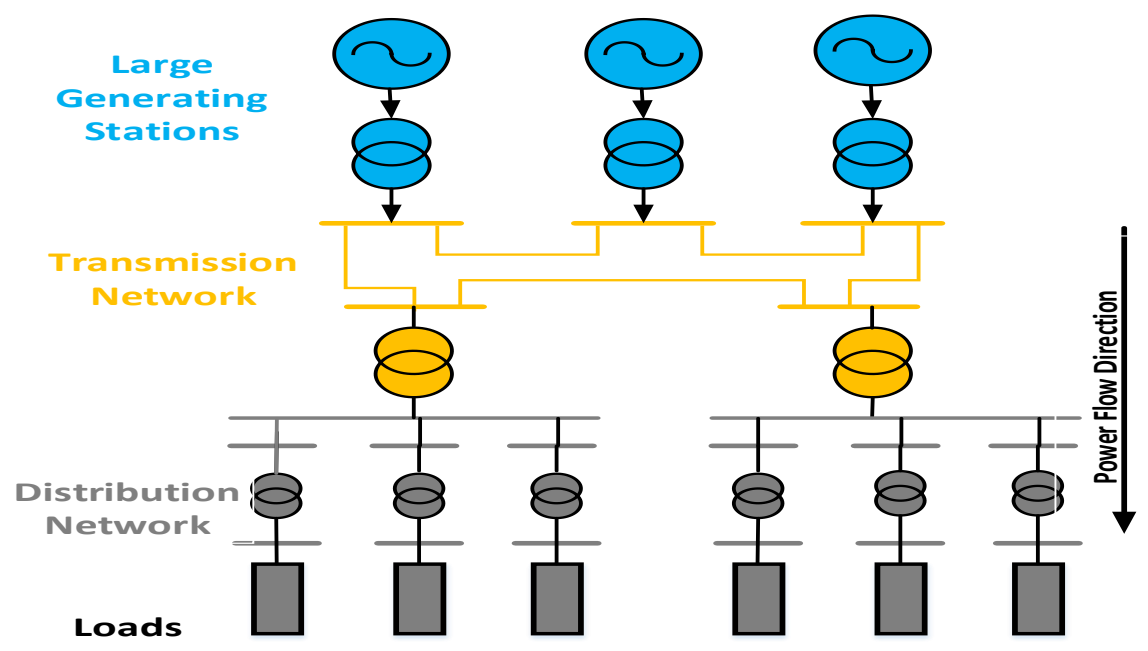

Figure 2. Conventional large electric power system.

The incorporation and integration of non-conventional or renewable energy sources in the network results to a new term called Distributed Generation (DG). DG can be defined as smallscale power generation units of electricity (a few kilowatts $\mathrm{kW}$ ) connected directly to the grid, distribution network, on consumer side of the meter to serve a customer on site and at the same time to provide the support to distribution networks or work standalone with different rating levels. Table 1 presented the generation of DG at different level [2]. 
Electrical Engineering: An International Journal (EEIJ) Vol.6, No.1/2, June 2019

Table 1. Generation of DG at different level [2].

\begin{tabular}{|l|l|l|}
\hline Item & Class & Size \\
\hline 1 & Micro distributed generation & $1 \mathrm{~W} \leq 5 \mathrm{~kW}$ \\
\hline 2 & Small distributed generation & $5 \mathrm{~kW}<5 \mathrm{MW}$ \\
\hline 3 & Medium distributed generation & $5 \mathrm{MW}<50 \mathrm{MW}$ \\
\hline 4 & Large distributed generation & $50 \mathrm{~W} \leq 300 \mathrm{MW}$ \\
\hline
\end{tabular}

The integration of DGs becomes the most economical solution to meet the increased demand due to load growth in the conventional system. While providing environmentally friendly energy and while helping to meet the increasing load economically. It can play an important role in electrical power network and by employing this technology in power systems has big advantages as following:

- Improving the reliability of the electrical network by providing an alternative source during power disturbance events.

- Reducing the electrical transmission power losses caused by the power traveling through long transmission lines and high voltage transformers.

- Providing better voltage support, used to supporting peak load and supply electricity during peak periods.

- Improving the power quality and enabling consumers to select the source of energy based on the cost and awareness of the environmental issues.

- Relieving the congested of electrical transmission networks and reducing the need to expand the electrical transmission networks.

- DGs considered as a viable alternative of energy storage alternative when interruptions are frequent. It works as Backup supply to ensures the uninterrupted electricity.

Currently, industrial countries generate most of their electricity in large centralized facilities, such as fossil fuel powered by coal or gas, nuclear, large solar power plants or hydropower plants. However, modern embedded systems can provide these traits with automated operation and renewables, such as sunlight, wind, and geothermal. Moreover, the last few years, a number of factors have led to an increased interest in distributed generation schemes such as availability of modular generating plant, ease of finding sites for smaller generators, short construction time and lower capital costs for smaller plant, reduction in gaseous emissions (mainly CO2).Due to the DG sources have a potential solution for some issues, like the deregulation in power system and improving the performance of distribution system as well as reliability evaluation, that is making it more popular. The presence of the DGs, especially when the DG share is significantly high, will obviously impact on way of power system operation. The distribution networks can be designed for (radial) unidirectional power flow, and the electric power systems with DGs spread across the distribution network is shown in figure 3. 
Electrical Engineering: An International Journal (EEIJ) Vol.6, No.1/2, June 2019

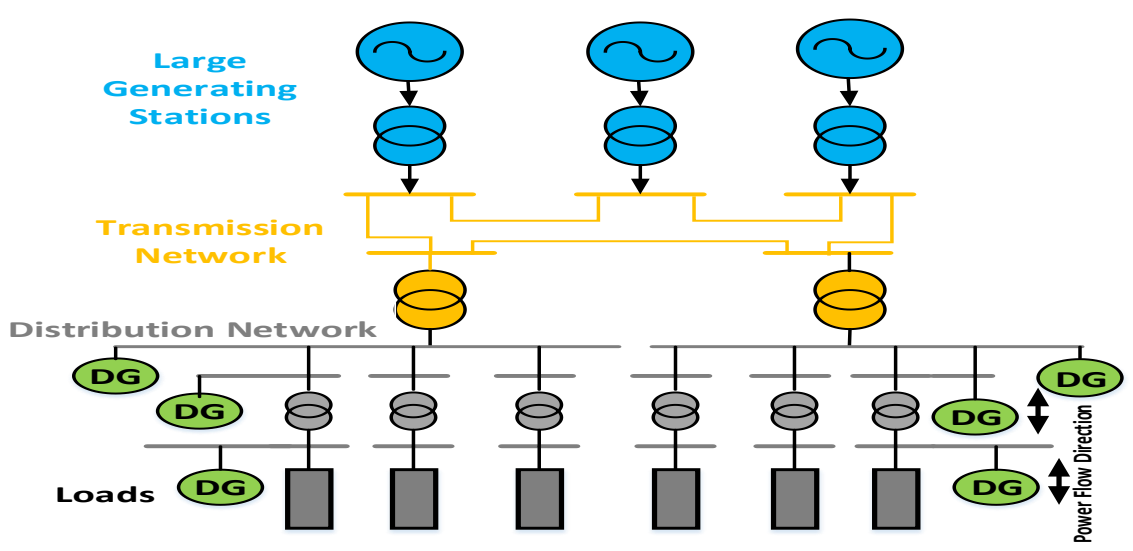

Figure 3. Electric power system with the presence of DGs.

In recent years there has been an increase in the global trend in general and particular in Kingdom of Saudi Arabia (KSA) towards finding and exploiting sources of renewable energy to generate electricity. This may be due to the urgent need for new and renewable sources of energy that are not fading and depleting. One of the reasons for this is that these sources limit the emission of toxic gases as well as saving energy costs and conserving their stocks from fossil sources (oil and natural gas) and not relying on it total. Due to the high prices of fossil fuels with the rapid rises in oil prices, capital costs of conventional power plants, escalation in power demand due to rapid growth in population and industrialization in the last several years especially in Saudi Arabia. The conventional generation, low quality fuels and the methods of generation typical in KSA is a chief cause of environmental pollution and impacts human health through emissions of harmful gases that are remains a threat to public health around the world. Therefore, it is essential to find green power source that reduce the gasses emission and preserves oil in Saudi Arabia. So, the renewable energy resources have been globally accepted for power generation, utilizing and integrated them with conventional generation around the globe. The solar radiation is variable in different parts of the world and the highest value of solar radiation located at sunbelt. Saudi Arabia is most suitable country over the world for using solar power and its solar irradiances are among the highest in the world because it located in the 'Global Sunbelt', a geographic region situated between $35^{\circ} \mathrm{N}$ and $35^{\circ} \mathrm{S}$. The generally characterized by high solar irradiation which can be witnessed in figure 4 .

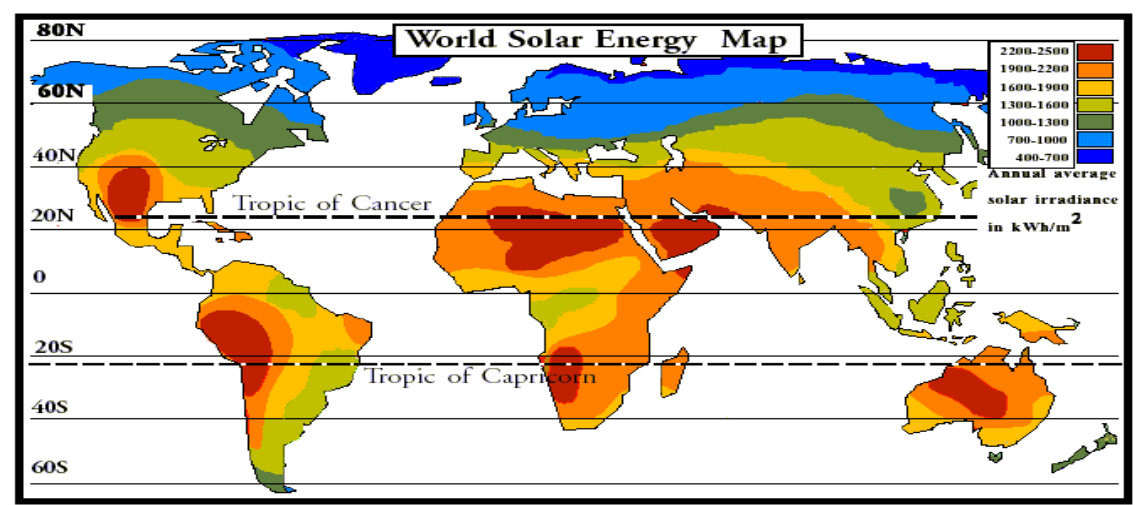

Figure 4. Best countries for using solar power source [3]. 
Electrical Engineering: An International Journal (EEIJ) Vol.6, No.1/2, June 2019

KSA has widespread desert land, year-round clear skies and abundant solar resource which it to become one of the largest solar photovoltaic (PV) energy producers in future and a world leader in renewable electricity generation. Studies show that the use of solar equipment in KSA is very suitable and can easily provide part of the energy that nation needs. The Several sources, including Snapshot of Global PV Markets 2016 [4], state that the total installed PV capacity at the end of 2016 was at least $303 \mathrm{GW}$. in addition, there is an estimated capacity of between 3000 GW and $10000 \mathrm{GW}$ expected to be installed by the year 2030 [5]. As part of the kingdom's 2030 vision, to build the largest PV generation plant over the world, and KSA aims to cut down overreliance on oil and gas as the principal sources of energy in the generation of electricity and KSA government is backing the process of energy source diversification to keep the oil for next generations. The KSA targeting to generate $3.45 \mathrm{GW}$ of renewable energy by 2020 and $9.5 \mathrm{GW}$ by 2022 [6]. In recent years the KSA was is ranked as the $12^{\text {th }}$ largest consumer of total primary energy in year 2013, of which about $60 \%$ is petroleum based and the rest was accounted to natural gas. Energy consumption per capita is twice that of Europe and three times the world average [6]. By the Year 2032, the electricity peak demand is anticipated to surpass 120GW [7]. The King Abdullah City for Atomic and Renewable Energy (KACARE) program seeks to ensure that half of the electricity generated in Saudi Arabia comes from renewable sources by 2032 [8].

\section{Solar RAdiation}

The solar resource and weather conditions of a place are often intermittent and prone to vary from one year to another year, so the datasets need to be compiled over a number of years to create historical site data. The statistical model of solar radiation is based on data for the solar irradiance at KSA-Riyadh, during period Jan 2013 - Jan 2016 which is available in King Abdullah City for Atomic and Renewable Energy's (K.A.CARE's) Renewable Resource Monitoring and Mapping (RRMM). Figure 5 shows the calculated distribution of the hourly average global, Direct, and diffuse of Solar Irradiance. Figure 6 shows the calculated monthly distribution average GHI of solar irradiance throughout the past time frame in Riyadh city.

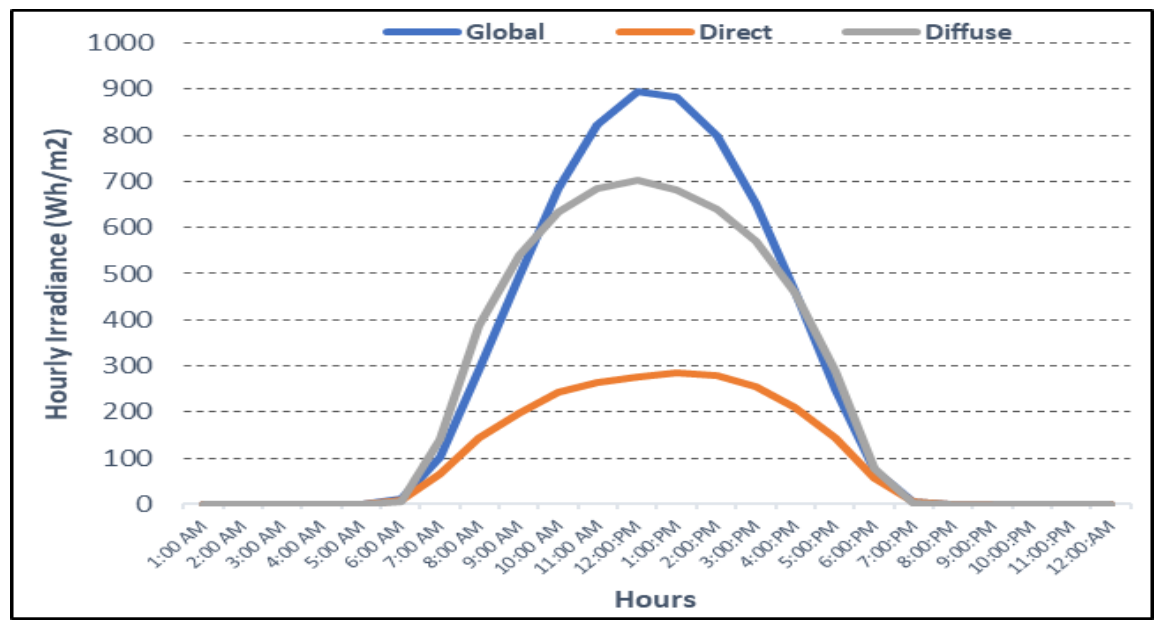

Figure 5: Hourly average DNI, DHI and GHI of solar irradiance (Wh/m2). 
Electrical Engineering: An International Journal (EEIJ) Vol.6, No.1/2, June 2019

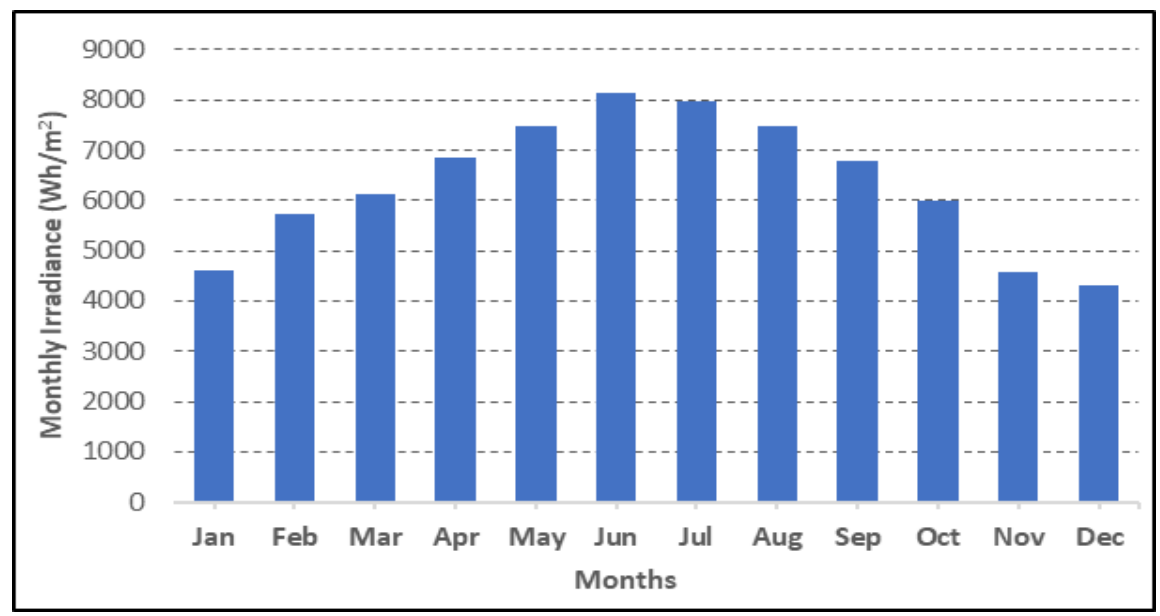

Figure 6. Monthly average GHI of solar irradiance $(\mathrm{Wh} / \mathrm{m} 2)$.

The solar radiation in Riyadh is characterized by long radiation period with high irradiance during summer and short radiation period with low irradiance during winter due to the differences in the sun's height at the summer and winter solstice. The solar irradiance is fluctuated from month to month based on the sun orbit. the highest value of monthly solar irradiance was for May, Jun, and July with maximum value $8,134(\mathrm{Wh} / \mathrm{m} 2)$ for Jun.

\section{Dg MOdeL}

It is well known that due to the fact that solar insolation is intermittent, and the output power of PV systems is not deterministic. for this reason, need for a stochastic model to simulate PV outputs. A stochastic model is a simulation-based technique to describe a non-deterministic behavior and the randomness of the system. The statistical data of solar insolation and temperature have been collected from (K.A.CARE's) and implemented in our study.

\subsection{Photovoltaic Power System Generation}

The Solar photovoltaic (PV) is widely used as renewable energy source. The solar of PV has a high reliability in modules (>20 years), and high public acceptance. PV is the technology that generates direct current (DC) electrical power measured in Watts (W) or kilo Watts $(\mathrm{kW})$ from semiconductors when they are illuminated by photons. As long as light is shining on the solar cell, it produces both a current and a voltage to generate electric power which is known as Photoelectric Effect [9]. A general representation of a grid-connected solar PV system is shown in figure 7. The most essential components in a grid-connected solar PV system are solar PV generator which consists of a large number of solar arrays, DC-DC converter, inverters, filter and step up transformers. A solar cell module produces only a small amount of current and voltage, and in order to produce a large amount of electric power, the solar cell modules are connected into arrays. The output voltage from a PV array changes with solar radiation and ambient temperature. Moreover, to connect the PV system to the transmission grid, the output DC voltage from PV system should be first regulated by a DC-DC converter. Then DC- AC inverter to converts the DC power produced by the PV modules into AC power. A filter is used to eliminate harmonics. The power electronic components have the tasks to guarantee safe and efficient operation, to track the maximum power point (MPP) of the PV system, and to maintain power 
Electrical Engineering: An International Journal (EEIJ) Vol.6, No.1/2, June 2019

quality of the PV system output. The transformer is an essential when the generated electricity is to be injected into the utility grid.

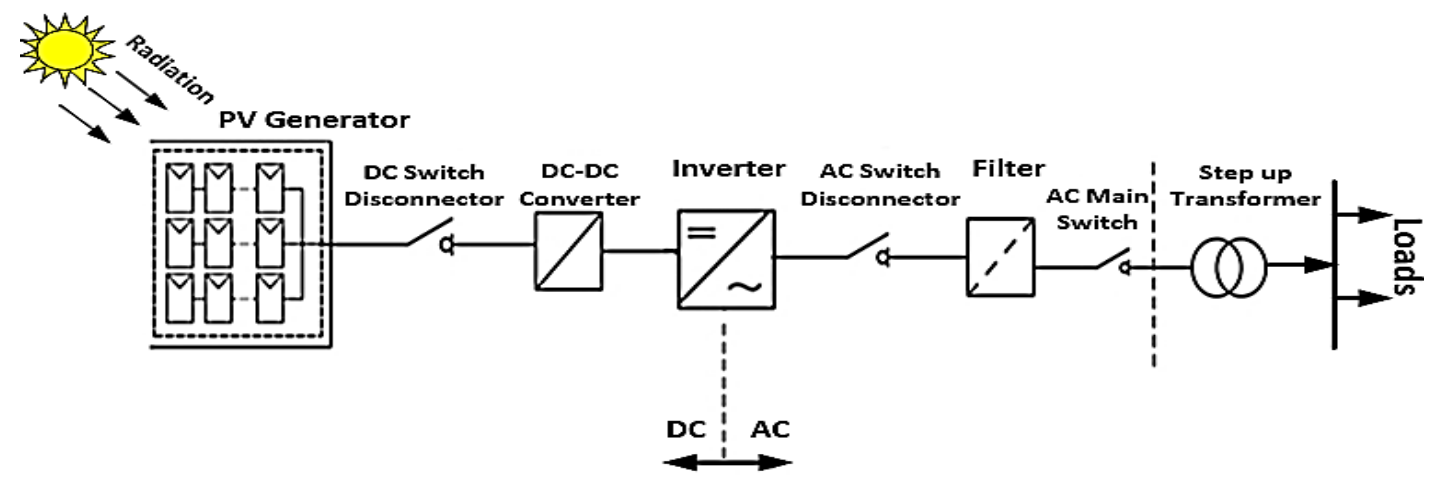

Figure 7. The schematic drawings of PV power system component.

\subsection{The Pv Module}

The ideal model of a solar cell consists of a photocurrent source and diode with an internal resistance connected to a parallel resistor. The current representing the photo generated current $\left(\mathrm{I}_{\mathrm{gc}}\right)$ in parallel with a diode which is directly proportional to the light falling (solar irradiation) on the cell. A PV cell is physically modelled using the equivalent circuit model as represented in figure 8 .

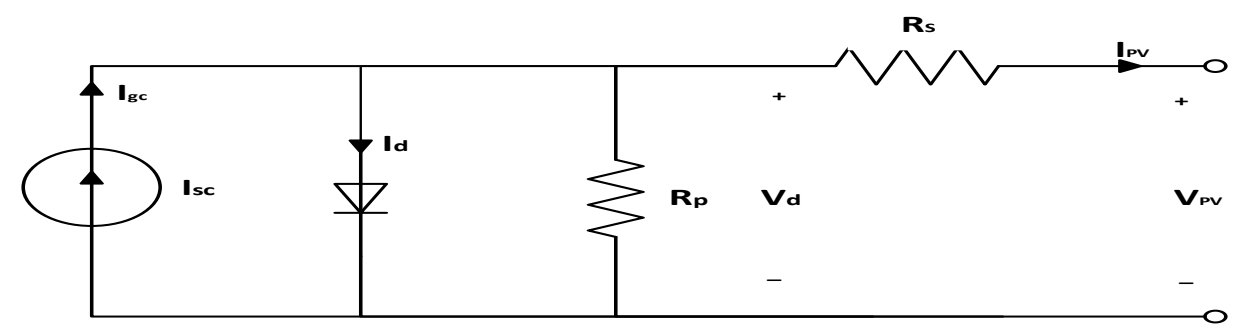

Figure 8. The PV equivalent circuit model.

Many researchers have been examined the general mathematical model description of a solar cell current-voltage output characteristic over the past three decades [10]. According to well know Kirchhoff's current law, the current flowing in the circuit can be modelled by the following equation (1) [11].

$$
\mathrm{I}_{\mathrm{PV}}=\mathrm{I}_{\mathrm{sc}}-\mathrm{I}_{\mathrm{o}}=\mathrm{I}_{\mathrm{sc}}-\mathrm{I}_{\mathrm{D}}\left[e^{\left(\frac{q V_{D}}{n K T_{\text {cell }}}\right)}-1\right]-\frac{V+I R_{S}}{\mathrm{R}_{\mathrm{P}}}
$$

Where: $I_{P V}$ is the PV output current. $I_{s c}$ Is the cell's short circuit current at $25^{\circ} \mathrm{C}$ and $1 \mathrm{KW} / \mathrm{m}^{2}$. $\mathrm{q}$ Is the electron charge equal to $1.602 \times 10^{-19} \mathrm{C}$. $\mathrm{k}$ Is the Boltzmann constant $\left(1.381 \times 10^{-23} \mathrm{~J} / \mathrm{K}\right)$. $\mathrm{V}_{\mathrm{D}}$ Is the voltage across the diode terminals. $\mathrm{V}$ Is the output voltage. $\mathrm{R}_{\mathrm{S}}$ and $\mathrm{R}_{\mathrm{P}}$ are the series and parallel resistances. $\mathrm{n}$ is the ideality factor, also known as the quality factor and usually takes values in the range 1 to 2 , which depends on the construction and semiconductor material listed in table 2 . 
Electrical Engineering: An International Journal (EEIJ) Vol.6, No.1/2, June 2019

Table 2. Ideality factor $n$ dependence on PV technology [12].

\begin{tabular}{|l|l|}
\hline Technology Type & Ideal Factor $(\mathbf{n})$ \\
\hline Si-Mono & 1.2 \\
\hline Si-Poly & 1.3 \\
\hline CdTe & 1.5 \\
\hline CIS & 1.5 \\
\hline
\end{tabular}

The cell's saturation current $\left(\mathrm{I}_{0}\right)$ varies with cell's temperature and depend on the cell temperature. As described by following equations (2),(3),(4),(5).

$$
\begin{aligned}
& \mathrm{I}_{\mathrm{gc}}=\left[\mu_{\mathrm{sc}}\left(\mathrm{T}_{\text {cell }}-\mathrm{T}_{\mathrm{r}}\right)+\mathrm{I}_{\mathrm{SC}}\right] \mathrm{G} \\
& \mathrm{I}_{\mathrm{D}}=I_{o}\left(e^{\frac{q V_{D}}{n K T_{\text {cell }}}}-1\right) \\
& \mathrm{I}_{\mathrm{o}}=\mathrm{I}_{\mathrm{o} \alpha}\left(\frac{\mathrm{T}_{\text {cell }}}{\mathrm{T}_{\mathrm{r}}}\right)^{3} \mathrm{e}^{\left[\frac{\mathrm{ev} \mathrm{d}}{\left.\mathrm{KF}\left(\frac{1}{\mathrm{~T}_{\mathrm{r}}}-\frac{1}{\mathrm{~T}_{\mathrm{c}}}\right)\right]}\right.} \\
& \mathrm{I}_{\mathrm{o} \alpha}=\frac{\mathrm{I}_{\mathrm{SC}}}{\mathrm{e}^{\left(\frac{\left.\mathrm{ev} \mathrm{v}_{o \alpha}\right)}{\mathrm{KFT}_{\mathrm{c}}}\right)}}
\end{aligned}
$$

Where: $I_{D}$ Is the diode current. $T_{\text {cell }}$ Is the cell's absolute temperature. $T_{r}$ Is the cell's reference temperature. $I_{o \alpha}$ is the cell's reverse saturation current at solar radiation and reference temperature. $\mathrm{G}$ is the Solar radiation in $\mathrm{kW} / \mathrm{m}^{2}$.

A solar cell alone can produce only output power from 1 to 2 Watt [13]. Furthermore, to increase the output power, the cell connected in series-parallel configuration on a module then array. A PV array is a group of several PV module and these arrays can be of sizes ranging from a few hundred watts to hundreds of kilowatts. The interconnection of PV modules in series and parallel or various other connections forms a PV array. The PV array composed of $\mathrm{N}_{S}$ series and $\mathrm{N}_{\mathrm{P}}$ parallel connected modules. And in order to calculate the generated photovoltaic current and the output power of a PV module consisted of ( $\mathrm{Ns} \mathrm{x} \mathrm{Np}$ ) cells as following equation (6).

$$
I_{P V}=N_{p} I_{g c}-N_{p} I_{o}\left[e^{\frac{e\left(\frac{v_{d}}{R_{s}}+s \frac{I R_{s}}{R_{p}}\right)}{N_{s} K_{c}}}-1\right]-\frac{\frac{N_{p} V_{d}}{N_{s}}}{R_{p}}
$$

\subsection{Non-Linear Characteristics Of PV's}

The Photovoltaics have nonlinear characteristics, where the performance and output power are directly affected with the change of the operating conditions solar irradiance, temperature and the angle of the sun. Usually the PV manufacturer supply their products with a data sheet that contains values of current and voltage for three conditions namely, the short circuit, the open circuit, and the maximum power for a given set of reference condition. The major inputs for the proposed PV model were solar irradiation, PV panel temperature and PV manufactures data sheet information. In this study, the Astronergy CHSM6610P Polycrystalline PV Module is taken as example to simulate it. The data sheet of the simulated module is shown in table 3 . 
Electrical Engineering: An International Journal (EEIJ) Vol.6, No.1/2, June 2019

Table 3. Astronergy CHSM6610P polycrystalline specifications.

\begin{tabular}{|l|c|}
\hline Electrical Specifications \\
\hline Maximum output power $\left(\mathrm{P}_{\mathrm{m}}\right)$ & $275 \mathrm{Wp}$ \\
\hline Voltage at $\left(\mathrm{P}_{\mathrm{m}}\right)\left(\mathrm{V}_{\mathrm{amp}}\right)$ & $31.12 \mathrm{~V}$ \\
\hline Current at $\left(\mathrm{P}_{\mathrm{m}}\right)\left(\mathrm{I}_{\mathrm{amp}}\right)$ & $8.85 \mathrm{~A}$ \\
\hline Short circuit current $\left(\mathrm{I}_{\mathrm{sc}}\right)$ & $9.52 \mathrm{~A}$ \\
\hline Open circuit voltage $\left(\mathrm{V}_{\mathrm{OC}}\right)$ & $38.45 \mathrm{~V}$ \\
\hline Temperature coefficient $\left(\mathrm{I}_{\mathrm{sc}}\right)$ & $+0.049 \% / \mathrm{C}$ \\
\hline Temperature coefficient for $\left(\mathrm{V}_{\mathrm{OC}}\right)$ & $-0.310 \% / \mathrm{C}$ \\
\hline Temperature coefficient $\left(\mathrm{P}_{\mathrm{m}}\right)$ & $-0.407 \% / \mathrm{C}$ \\
\hline Number of cells / cell arrangement & $60 / 6 \times 10$ \\
\hline
\end{tabular}

An insolation-oriented model of PV module is built by using MATLAB to illustrate and verify the nonlinear $\mathrm{I}-\mathrm{V}$ and $\mathrm{P}-\mathrm{V}$ output characteristics of $\mathrm{PV}$ module. Both $\mathrm{I}-\mathrm{V}$ and $\mathrm{P}-\mathrm{V}$ output characteristics of PV module at various insolation and temperatures based on Riyadh region data are carried out. Figures 9 and 10 show the effect of changing the temperature and solar irradiance on PV's output current, voltage, and power as well.
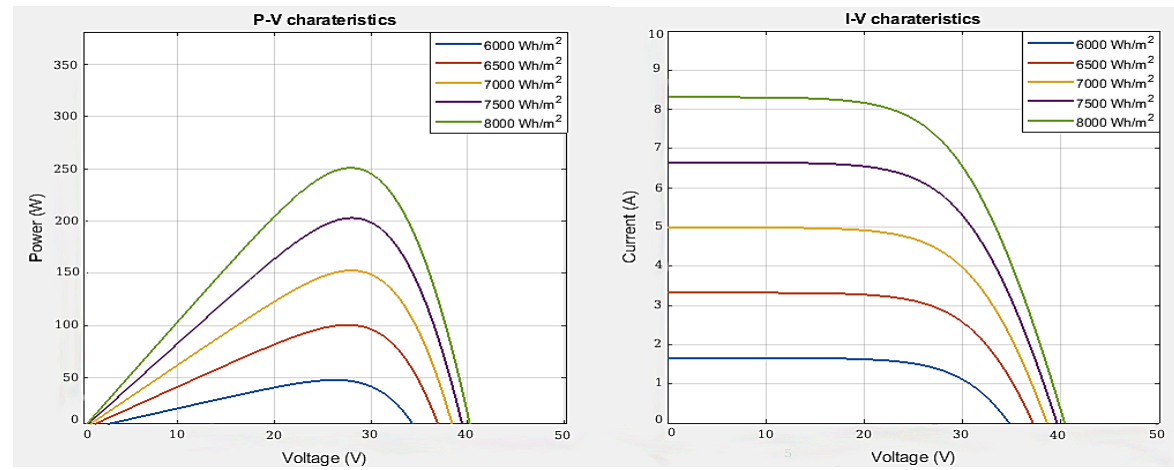

Figure 9. The irradiance changing effect on I-V and P-V output characteristics.
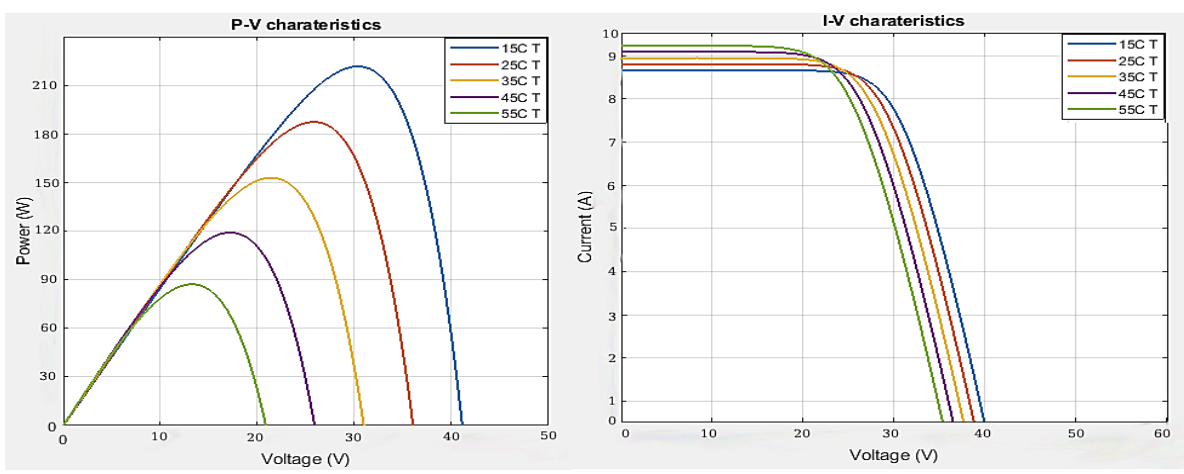

Figure 10. The temperature changing effect on I-V and P-V output characteristics.

It is clear from the previous figures that the output power of PV's is directly proportional with the amount of solar irradiance falling on PV's panel, and inversely proportional with its temperature. We can see the effect of change in solar irradiation on PV characteristics from figure 9. It is 
Electrical Engineering: An International Journal (EEIJ) Vol.6, No.1/2, June 2019

illustrated that as we increase the solar irradiation short circuit current increases, and current increases from 1.8 A to 8.3 A approximately. The effect of variation of solar irradiation on P-V characteristics result that as solar irradiation increases, power generated increases also. Increase in power is mainly due to increment in current. Decreasing the irradiance will reduce the overall performance of the PV module. On other hand, we observe from figure 10 that, with an increase in the temperature the maximum power output of $\mathrm{P}-\mathrm{V}$ curves are decreases whilst the short circuit current decrease also. As the temperature increases, the efficiency of the panel decreases. We can see the variation of temperature on I-V curves mostly effects voltage, as we increase the temperature, voltage decreases but current remains almost unaltered.

\subsection{The Pv Output Power Model}

The PV output power system was proposed to assess the reliability of distribution system containing renewable energy resources (solar energy generation plants with different capacity). The PV system output power can be calculated by the following equation (7), [14]:

$$
\mathrm{P}(\text { out })= \begin{cases}\frac{\eta_{\mathrm{C}}}{\mathrm{K}} * \mathrm{~S} * \mathrm{I}(\mathrm{t})^{2} & 0<\mathrm{I}(\mathrm{t}) \leq \mathrm{K} \\ \eta_{\mathrm{C}} * \mathrm{~S} * \mathrm{I}(\mathrm{t}) & \mathrm{I}(\mathrm{t})>\mathrm{K}\end{cases}
$$

Where $\left(\eta_{C}\right)$ is the efficiency of the PV system, $\mathrm{K}$ is a threshold and $\mathrm{I}(\mathrm{t})$ is the hourly solar insolation. The value of $\left(\eta_{C}\right)$ is not constant when $I(t)$ is less than or equal, it is proportional with the solar insolation. That means when the solar insolation increase the PV system efficiency will increase and vice versa. The following equation (8) can be express the hourly solar insolation [15].

$$
I(t)=\left\{\begin{array}{lc}
I \max \left(-\frac{1}{36} t^{2}+\frac{2}{3} t-3\right) & 6 \leq t \leq 18 \\
0 & 0 \leq t<6 \text { and } 18 \leq t \leq 24 \geq 0
\end{array}\right.
$$

\section{LOAD MODEL}

The load modelling is an important part of power system modelling process and has a significant effect on power system simulation results. The load model is created by using daily or monthly or yearly peak loads with respect to time in seconds or minutes or hours. The energy consumption can be displayed with load curve as shows the amount of demand used per period of time but Load Duration Curve (LDC) shows the amount of maximum ranking until the minimum demand is used. LDC is the basic tool used in the analysis of electric power systems such as estimating the operating cost of resource plans, and as tool to integrate the demand side management in the planning of electricity generation and enables to evaluate the operation of the power system more accurately than the traditional approach. Figure 11 shows LDC displaying various load-related variables. This load duration curve has a shape of a monotonously decreasing function and in this load duration curve, we can know that the slope varies according to time. 
Electrical Engineering: An International Journal (EEIJ) Vol.6, No.1/2, June 2019

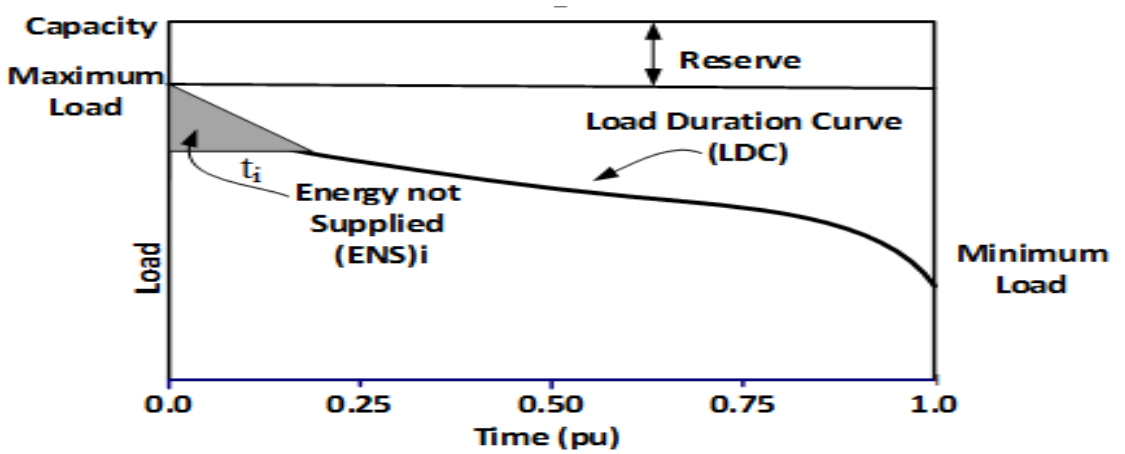

Figure 11. Load duration curve displaying various load-related variables.

Over the last several years, the peak of electricity demand in Kingdom of Saudi Arabia (KSA) is continuously increasing. The Saudi Electricity Company (SEC) operates an interconnected transmission system for all main areas in KSA. SEC system is divided into four operating areas, named as Central, Eastern, Western and Southern Operating areas. Since Riyadh city is the major load center in Central operating area it faces unique issues in every day operation of the system [16]. Figure 12 and 13 show the measured average values of daily and monthly electrical energy consumption in Riyadh city in the year 2018. It can be observed that the summer months from June to October have consistently higher loads than the non-summer months.

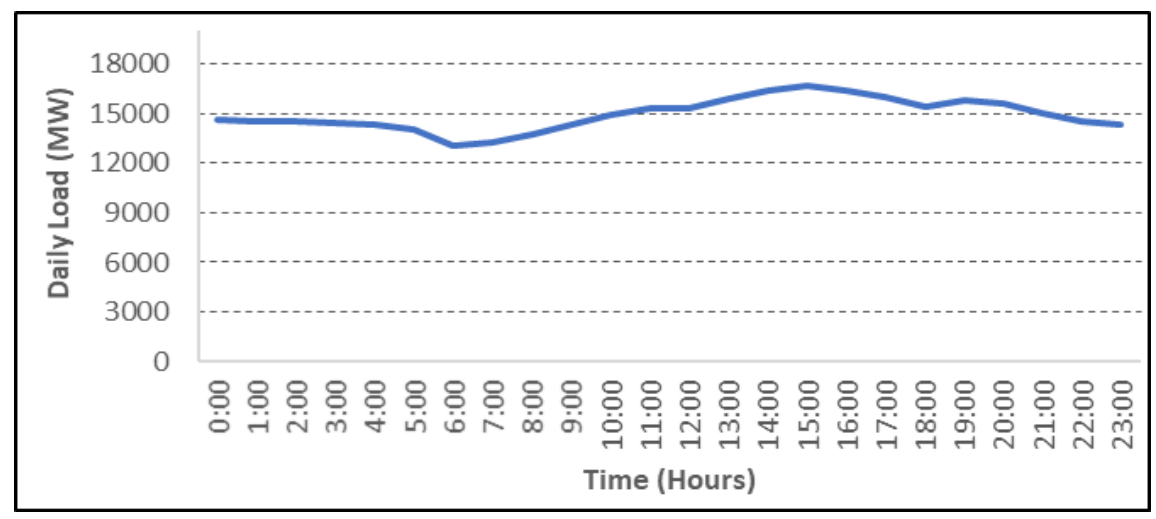

Figure 12. Variation of daily average load demand of Riyadh city in the year 2018.

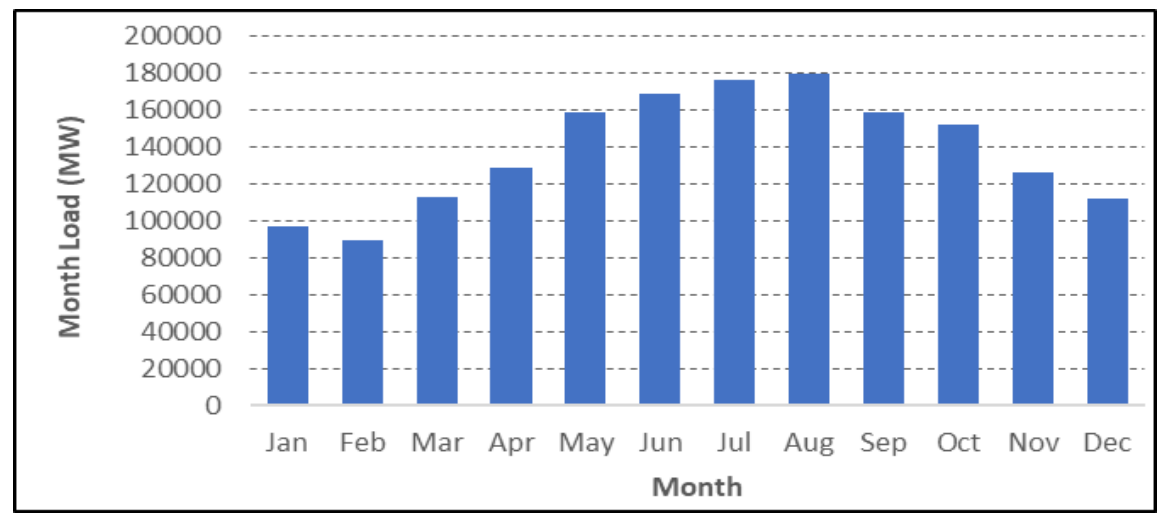

Figure 13. Variation of monthly average load demand of Riyadh city in the Year 2018. 
The behavior of power system loads is a frequent pattern during normal conditions, and a time varying load model can be developed by using historical data. The model used in this study is the hourly load curve which can be converted to load duration curve by arranging the data in descending order. The following equation (9) used to find the predicated the load for any load point at any desired time.

$$
\mathrm{P}_{\mathrm{i}}=\mathrm{W}_{\mathrm{h}}(\mathrm{h}) \times \mathrm{W}_{\mathrm{m}}(\mathrm{m}) \times \mathrm{P}_{\mathrm{Li}}
$$

Where, $W_{h}(h)=$ hourly weight factor, $W_{m}(m)=$ monthly weight factor, and $P_{L i}=$ peak load for load point.

\section{SYSTEM RELIABILITY INDICES}

The basic function of an electric power system is to supply customers with reasonably economical and reliable electricity. The reliability level of one distribution system are often evaluated from two aspects which are consumer level and system level. These two frequently used reliability indices for users of load points are as follow. The first one is average failure rate $\left(\lambda_{\mathrm{i}}\right)$ which is number of outages/year and defined as the probability of failure occurrence during a specific period for load point. The second one is average annual interruption time $\left(U_{i}\right)$ which is sum of the outages time/year and defined as the average interruption time of load point in a specific period. These two indices can be expressed as following equations (10), (11); [17].

$$
\begin{aligned}
& \lambda=\sum_{i=1}^{n} \lambda_{i} \\
& \mathrm{U}=\sum_{i}^{n} \lambda_{i} \mathrm{r}_{i}
\end{aligned}
$$

Where $\lambda_{i}$ is the failure rate of the series components from the source point to load point, $\mathrm{n}$ is the total number of components which affect load point, $r_{i}$ is average restoration time of network component to restore load point $i$ due to the failure of component $j$.

The commonly reliability induces of the system defined as functions of average failure rate over the total number of customers, and average interruption time [17]. The reliability system indices measure by some factors which can be aggregated to provide an appreciation of the system performance using a series of system indices such as System Average Interruption Frequency Index (SAIFI) which refers to the ratio of the total number of customer interruptions to total number of customers served and is the number of permanent interruption that customers would experience in one year. System Average Interruption Duration Index (SAIDI) which refers to the ratio of the sum of customer interruption durations to total number of customers and usually measures the duration of permanent interruption that customers would experience in one year. Customer Average Interruption Duration Index (CAIDI) which refers to the ratio of the sum of customer interruption durations to total number of customer interruptions and is the average time needed to restore service to the average customer per sustained interruption. Expected Energy Not Supply ( $\epsilon$ ENS) measures the total of energy interruption that customers would experience in one year and its dimension (MWh/year). these indices which can be calculated by following equations (12), (13), (14), (15); [17], [18]. 
Electrical Engineering: An International Journal (EEIJ) Vol.6, No.1/2, June 2019

$$
\begin{aligned}
& \text { SAIFI }=\frac{\sum_{i=1}^{n} \lambda_{i} \mathrm{~N}_{i}}{\sum_{i=1}^{n} \mathrm{~N}_{i}} \\
& \text { SAIDI }=\frac{\sum_{i=1}^{n} U_{i} \mathrm{~N}_{i}}{\sum_{i=1}^{n} \mathrm{~N}_{i}} \\
& \text { CAIDI }=\frac{\sum_{i=1}^{n} U_{i} \mathrm{~N}_{i}}{\sum_{i=1}^{n} \lambda_{i} \mathrm{~N}_{i}}=\frac{\text { SAIDI }}{\text { SAIFI }} \\
& \epsilon \mathrm{ENS}=\sum_{i=1}^{n} \mathrm{E}_{i} \mathrm{~N}_{i}
\end{aligned}
$$

Where $\mathrm{N}_{i}$ is number of customers at load points i, $U_{i}$ is the annual outage time, $\mathbf{N}_{i}$ is the number of customers at load point $\mathrm{i}, \mathrm{E}_{i}$ is the average of average interruption energy per load point.

\section{Monte Carlo Simulation}

Monte Carlo Simulation (MCS) has been used in reliability evaluation of distribution systems to simulate the failures due to that failures in power system networks are random in nature. It is a powerful method for solving a complex system and often used in complex mathematical calculations, stochastic process simulations, engineering system analysis and reliability calculation. MCS is a probabilistic method that can be used to predict the behavior of the system components which in real time will be all different in varying degrees, including the number of failures, times to failure, restoration times. The Simulation techniques used to estimate the reliability indices by simulating the actual process and random behavior of the system. The time sequential simulation is one of the MCS types used when the system behavior depends on past events to examine and predict behavior patterns in order to obtain the probability distributions of the various reliability parameters. The system reliability indices can be obtained from the artificial history that needed in time sequential simulation, and this can be obtained by generating the up (where expressed the element is in the operating state) and down (where expressed the element is inoperable due to failure) times randomly for the system elements. These artificial histories depend on the reliability parameters the elements and the system operating /restoration modes.

Time to failure (TTF) or failure time (FT) is the duration that it would take the component to fail or the time during the element remains in the up state. This time is predicted randomly and calculated by the following equation (16); [17], [18].

$$
T T F=-\frac{1}{\lambda} \times \ln (n)
$$

Where $\lambda$ is failure rate of system component and $\mathrm{n}$ is a random number (range from 0 to 1 ).

Time to repair (TTR) or time to replace (TTR) is the time required to repair a failed component or the time during the element remains in the down state and it is used to indicate the cycle time of failure. Also, this time is predicted randomly by the following (15); [17], [18]. 


$$
T T R=-\frac{1}{\mu} \times \ln (n)
$$

Where $\mu$ is repair rate of system component.

The process of transiting from the up state to the down state is the failure process and can be caused by the failure of an element or by the removal of elements for maintenance time. The parameters TTF and TTR are random variables and it is obvious from equations (14) and (15) that TTF and TTR follow exponential distributions. So, to predict the artificial history of system components, TTF and TTR can be generated to cover simulation times (e.g. one year) in chronological order. MCS have to be performed for a large number of scenarios, and the simulation time can be expanded to be a very long time (e.g. a thousand years or more) depending on the case study and also the desired accuracy. After that, the average can be calculated. Figure 14 shows an example of simulated component operating/restoration history of a component.

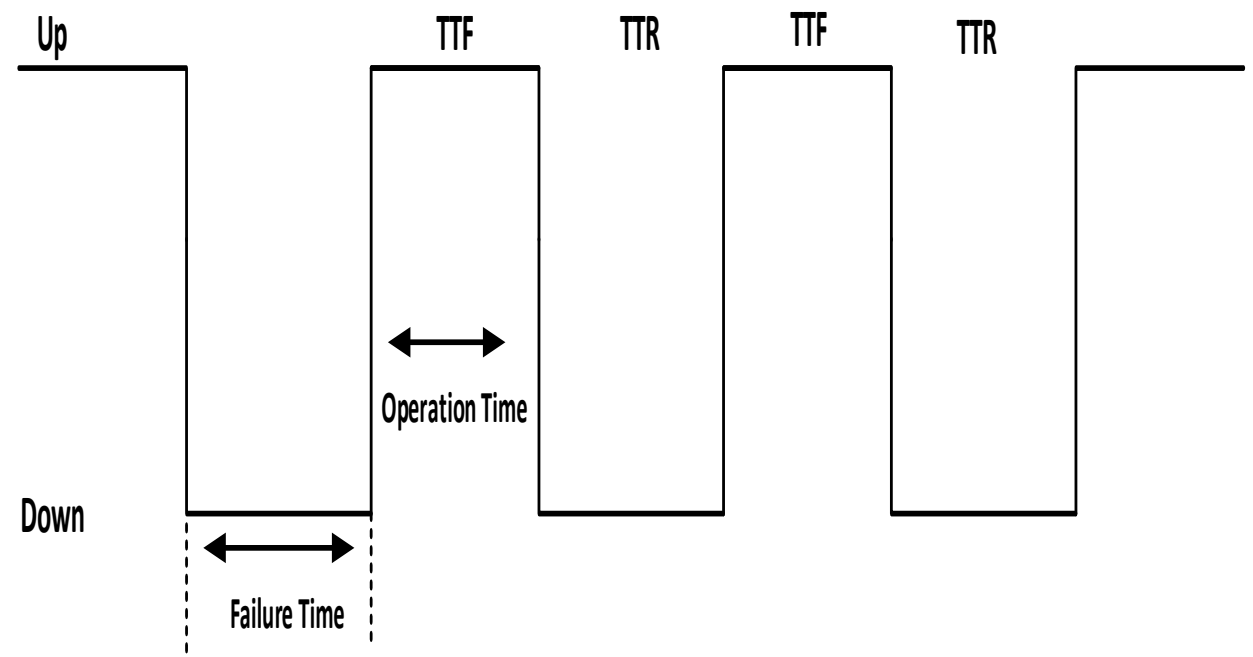

Figure 14. Element operating/repair history [17].

The element failures might have influence on one or additional load points and the most difficult in the simulation is to search out the load points and their failure period that affected by the failure of an element which are dependent on the network configuration. And in order to get a clear vision of how adding DGs impact on the reliability evaluation results of networks. We have used two reliability evaluation algorithms which are MV network that does not contain DGs of PV and a MV network that containing DGs of PV.

As the main purpose of this study is to evaluate the reliability of MV network system with renewable energy resource which is the PV distributed generation with vary output power capacity to see their impact on the reliability, the following assumptions were created that shouldn't have a major impact on the results:

a. The permanent faults only are included in the study and all protection devices operate with success to isolate the faults.

b. The primary main feeder failures only are included in the analysis and Every section protected by a breaker to isolate the faults. 
Electrical Engineering: An International Journal (EEIJ) Vol.6, No.1/2, June 2019

c. It takes one hour to transfer the loads from the failed feeder to a neighboring feeder through a normal operating point.

d. Each circuit breaker is controlled by a bi-directional protection device.

The simulation procedures of reliability evaluation of distribution networks do not contain and contain renewable energy of PV distributed generators are shown in figures 15 and 16. It shows the algorithms of distribution system reliability evaluation indices without and with PVs distributed generators respectively.

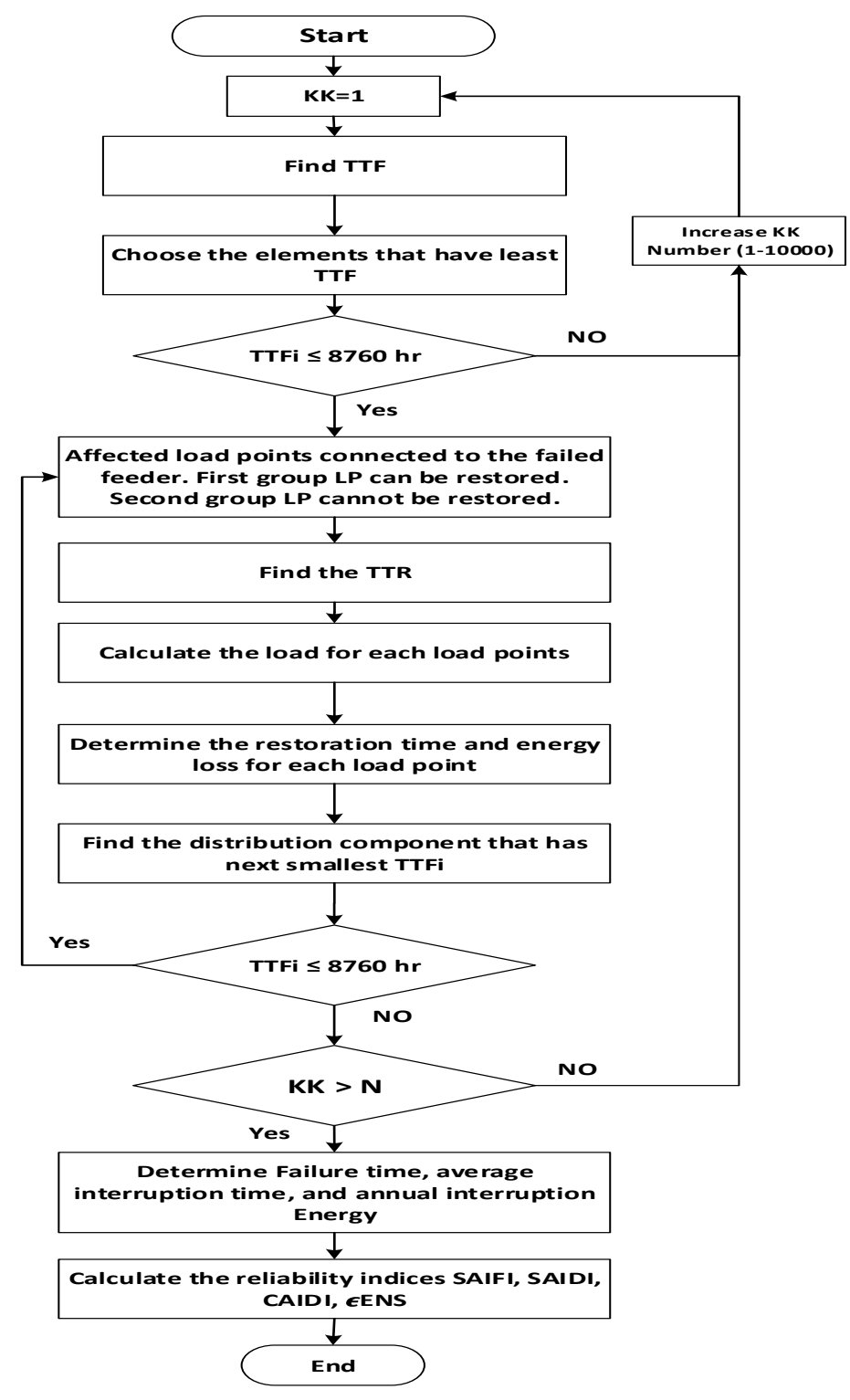

Figures 15. Flowchart of distribution system reliability evaluation without DGs of PV. 
Electrical Engineering: An International Journal (EEIJ) Vol.6, No.1/2, June 2019

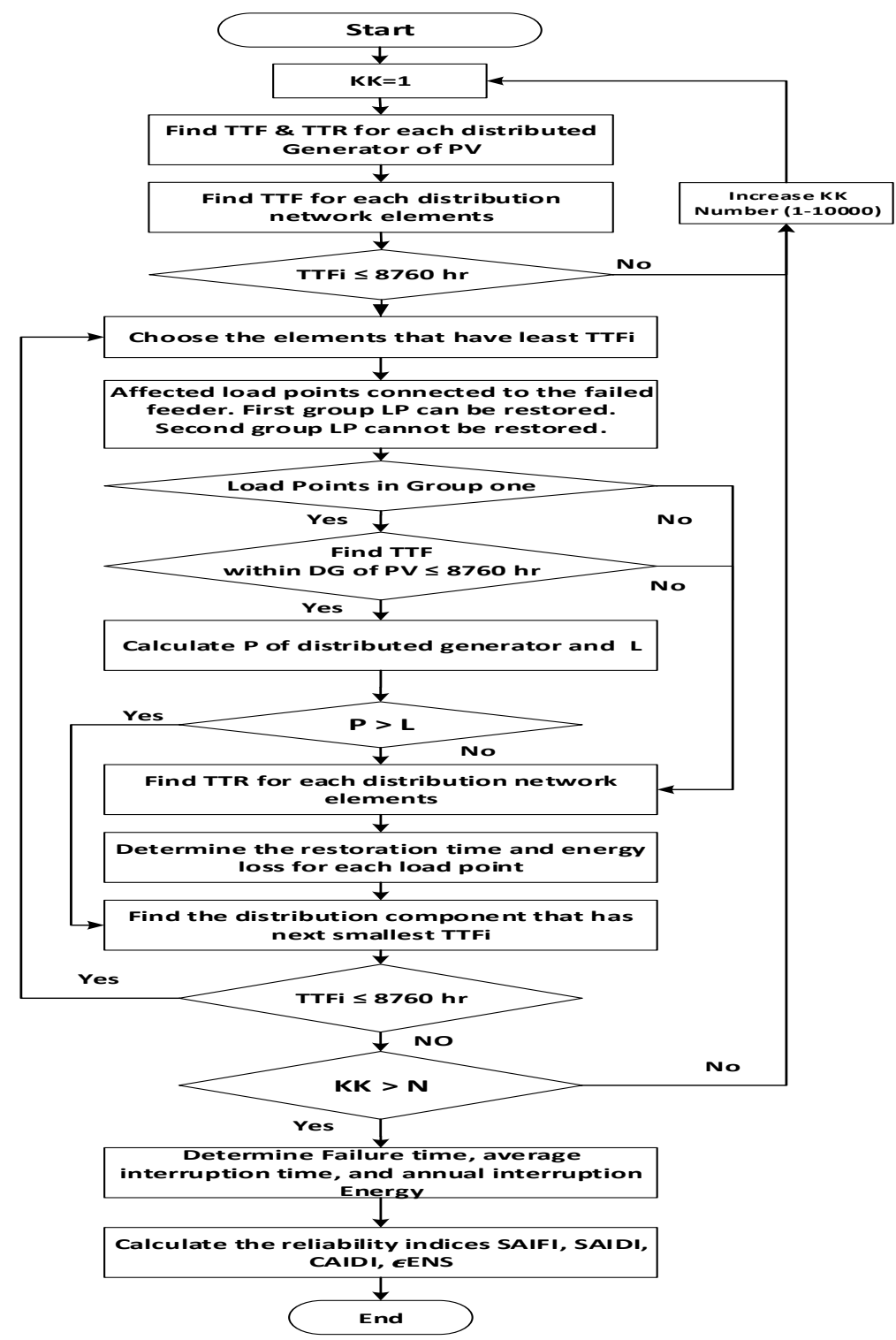

Figures 16. Flowchart of distribution system reliability evaluation with DGs of PV.

\section{Case Study Application}

Many researchers have been studied the distribution network reliability and used the RBTS Bus 2 or Bus 4. Moreover, substation number 7029 MV distribution network in Riyadh region has selected similarly to conduct the reliability evaluation study and compare the results with RBTS Bus 2. These networks offer the information needed to conduct a reliability study. The RBTS bus 2 is supplied by two 33/11 kV, 16 MVA transformers whereas the substation 7029 is supplied by two 33/13.8KV, 20MVA transformers. The $0.415 \mathrm{KV}$ and $0.400 \mathrm{KV}$ low voltage customers are supplied via $11 / 0.415 \mathrm{KV}$ and $13.8 / 0.400 \mathrm{KV}$ transformers, whereas the $11 \mathrm{kV}$ and $13.8 \mathrm{KV}$ customers are supplied directly. For the reliability analysis the $33 \mathrm{kV}$ supply has been considered $100 \%$ reliable and the feeders are operated as radial feeders but connected as a mesh through normally open sectionalizing points. Following a fault on a feeder, the ring main units permit the sectionalizing point to be moved and customers to be supplied from alternative supply points. 
Electrical Engineering: An International Journal (EEIJ) Vol.6, No.1/2, June 2019

Figures 17 and 18 show the modified single line diagram for the distribution networks system of RBTS bus 2 and substation 7029 with DGs of PV.

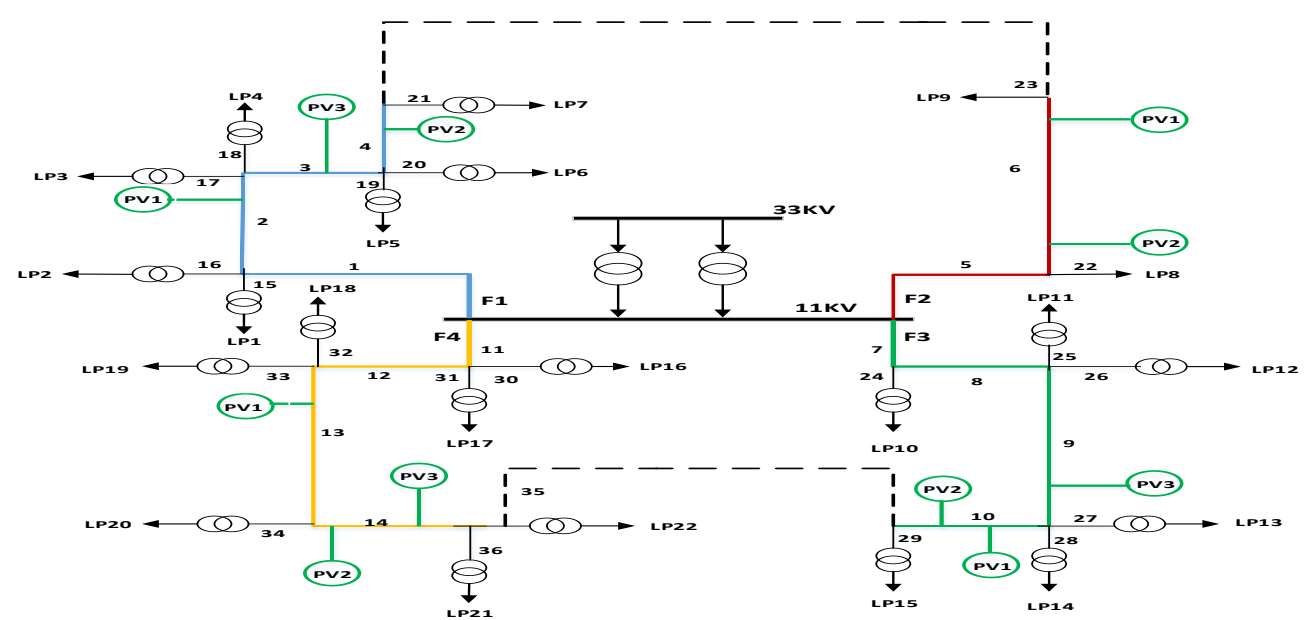

Figure 17. Distribution system for RBTS Bus 2 with PV DG.

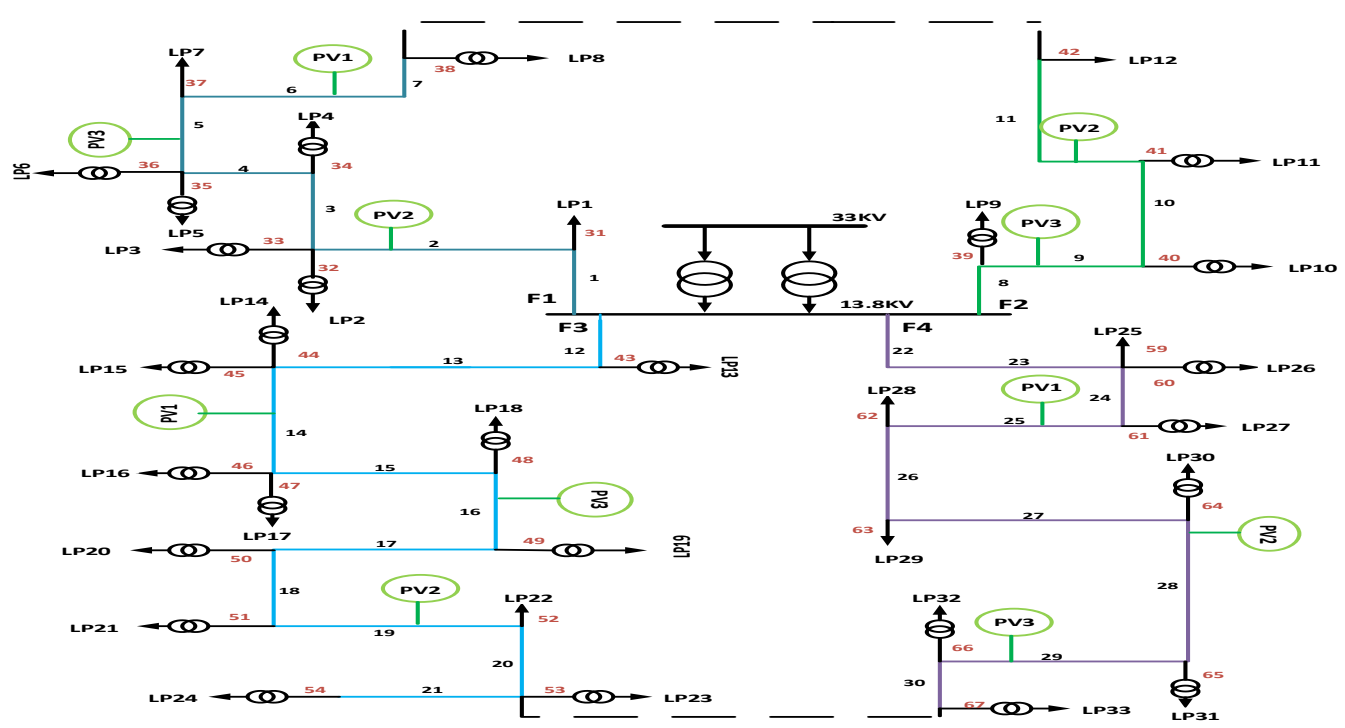

Figure 18. Distribution network for MV substation 7029 with PV of DG.

The data of RBTS Bus 2 distribution network may be found in reference [19]. The modified RBTS and substation 7029 have one type of distributed generator, is photovoltaic solar energy with vary of output power capacity. The maximum output power of PV1, PV2 and PV3 is $200 \mathrm{KW}, 400 \mathrm{KW}$ and $800 \mathrm{KW}$. The failure rate of PV1, PV2 and PV3 generators are taken as $0.11,0.15$ and $0.21 \mathrm{f} / \mathrm{yr}$ respectively. The average repair time for DGs of PV are taken as 32,31 and $30 \mathrm{hr}$ respectively. The all distributed generators of RBTS and substation 7029 contain all feeders (1,2,3 and 4) and are supplied by PV1, PV2 and PV3, except feeder 2 of RBTS and substation 7029 due to this feeder has less numbers of load points. The distributed generators of $\mathrm{PV}$ can operate in islanded mode, if there is enough power generation to supply the feeders loads during a permanent fault. We have used MCS in this work to evaluate the reliability indices of RBTS bus 2 and substation 7029 without DGs of PV and with DGs of PV. In addition, the impact 
of implementing these technologies in the reliability assessment of the distribution network are investigated. The annual average rate, average interruption time, and annual interruption energy of load points for RBTS and substation 7029 in two cases without and with DGs of PV are shown in figures 19, 20, and 21 respectively.

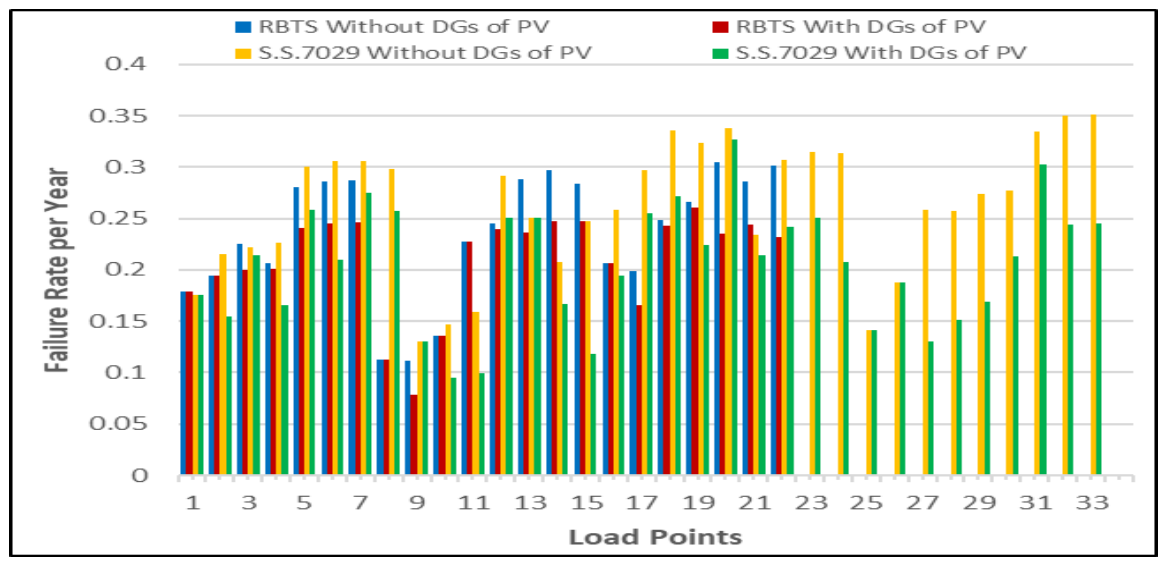

Figure 19. Annual average failure rate for all load points of RBTS and S/S7029.

The RBTS and Substation 7029 failure rate of the feeder section is a function of the length. However, each section has a different length which resulted the failure rates of the short feeder (F2) are low compared to the long feeders (F1, F2 and F4) of RBTS network. In addition, the failure of loads on the short feeder (F2) are also low compared to loads on the long feeders (F1, F3, F4) in the substation 7029. In the RBTS bus 2 and substation 7029 without distributed generators, it is obvious that the load points located at the end of the main feeder have high failure rates compared to the loads in the beginning of main feeder, because permanent faults result in isolating these load points from the main source. On the other hand, the load points with distributed generators of PV located at the end of the main feeder have low failure rates. This reduction in failure rate due to the excess generation capacity provided by the DGs during the outage of the main sources. From figure 19, it is obvious that there is no reduction and improvement in the average failure rates for load points 1, 2, 8, 10,11 and 16 in the RBTS and load points 1, 9, 13, 25 and 26 in the substation 7029 Since a probabilistic simulation was used in this study.

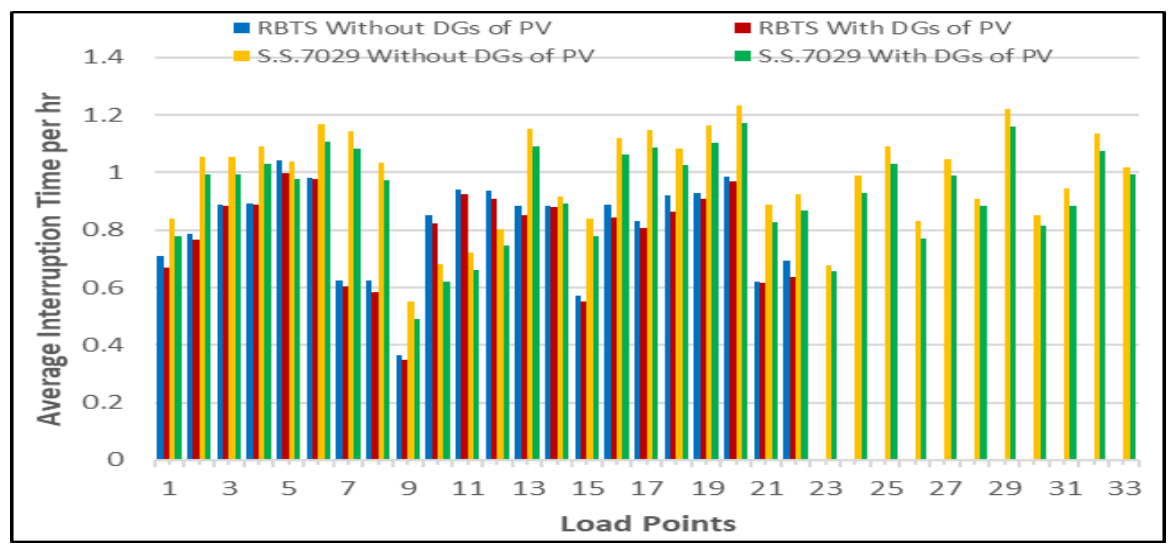

Figure 20. Average interruption time for all load points of RBTS and S/S7029. 
The average interruption time is a function of failure rates and average restoration time of RBTS and substation 7029 network components. Therefore, the all previous observations are applicable to figure 20. As a result, it is observed from figure 20 that RBTS and substation 7029 with DGs of $\mathrm{PV}$ can reduce the average interruption time for most of load points slightly. Comparing the result between RBTS Bus 2 and substation 7029 it demonstrated that the average interruption time of substation 7029 is higher than RBTS Bus 2 due to has a greater numbers of load points and long lines. The calculated average interruption time for all load points of substation 7029 without and with DGs of PV is 32.305 per hour and 30.556 per hour. Whilst, the RBTS Bus 2 has total of average interruption time without and with DGs of PV are 17.847 per hour and 17.309 per hour.

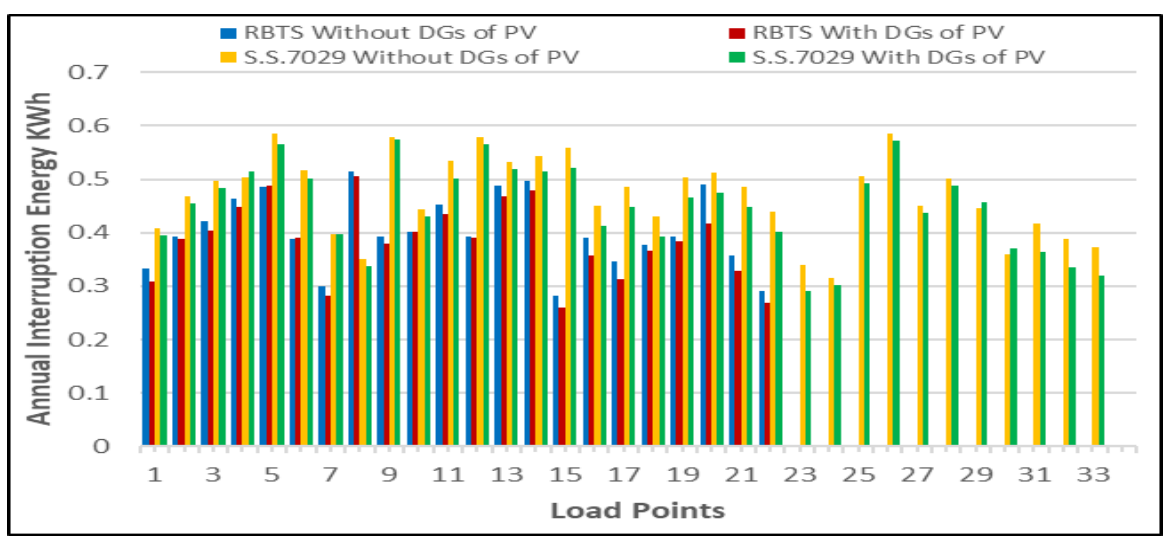

Figure 21. Average interruption energy for all load points of RBTS and S/S7029.

The average interruption energy of all load points is described as a function of the average interruption time and the load of each load point. Therefore, all of the previous observations and clarifications are applicable to figure 21. It is obvious that most of the load points have a little improvement in interruption energy after adding DGs of PV. Table 4 shows the results of the overall reliability indices of the entire system for RBTS Bus 2 and substation 7029 for the two cases (without and with DGs of PV). All cases are using the method proposed in this study.

Table 4. Reliability indices of RBTS Bus 2 and substation 7029.

\begin{tabular}{|l|l|l|l|l|}
\hline Index & $\begin{array}{l}\text { RBTS } \\
\text { W/O DGs }\end{array}$ & $\begin{array}{l}\text { RBTS with } \\
\text { DGs }\end{array}$ & $\begin{array}{l}\text { S.S.7029 W/O } \\
\text { DGs }\end{array}$ & $\begin{array}{l}\text { S.S.7029 with } \\
\text { DGs }\end{array}$ \\
\hline SAIFI (Inter./customer yr) & 0.2098 & 0.1918 & 0.3514 & 0.2827 \\
\hline SAIDI (hr/customer yr) & 0.8745 & 0.8462 & 0.9017 & 0.8814 \\
\hline CAIDI (hr/customer inter.) & 4.1682 & 4.4118 & 2.5660 & 3.1177 \\
\hline eENS (MWh/yr) & 8.3848 & 8.0246 & 8.9307 & 8.5821 \\
\hline
\end{tabular}

It is observed that from the previous study and results, the implementation of DGs of PV in distribution networks can improve the reliability of distribution networks by offering a backup source when the main source is not available. In addition, the overall reliability indices have improved after adding DGs of PV which is shown in Table 4. Based on the previous figures 19, 20 and 21 we observe that the reliability improvement associated in the presence of network with distributed generators not only depend on the size of DGs but the location of DGs is play an important role also. The DGs of PV integration have a positive impact on whole system reliability irrespective of the penetration level or the existing conditions. The summary of these system 
Electrical Engineering: An International Journal (EEIJ) Vol.6, No.1/2, June 2019

reliability indices (SAIFI, SAIDI, CAIDI and $\epsilon$ ENS) are shown in figure 22. SAIFI has least impact and lowest interruptions per customer on RBTS Bus 2 distribution network. The reliability indices of distribution networks (SAIDI) affected very slightly after adding DGs of PV. RBTS Bus 2 has the highest impact on system reliability indices (CAIDI) than S.S 7029. As the faulted feeder and all load points suffer power outage when a fault occurs either at any location between feeders and main bus or at any feeder circuit breaker or on the main bus. Thus, it has highest impact on $\in$ ENS. We observed that, there is a slight improvement after adding DGs of PV for two distribution networks. RBTS Bus 2 has better system reliability ( $\epsilon$ ENS) than S.S 7029. These reliability indices (SAIFI, SAIDI, CAIDI and $\in$ ENS) can be used to determine the system performance of the composite distribution system. The system reliability indices can also be used to make assessment for the severity of system failures on future reliability analysis.

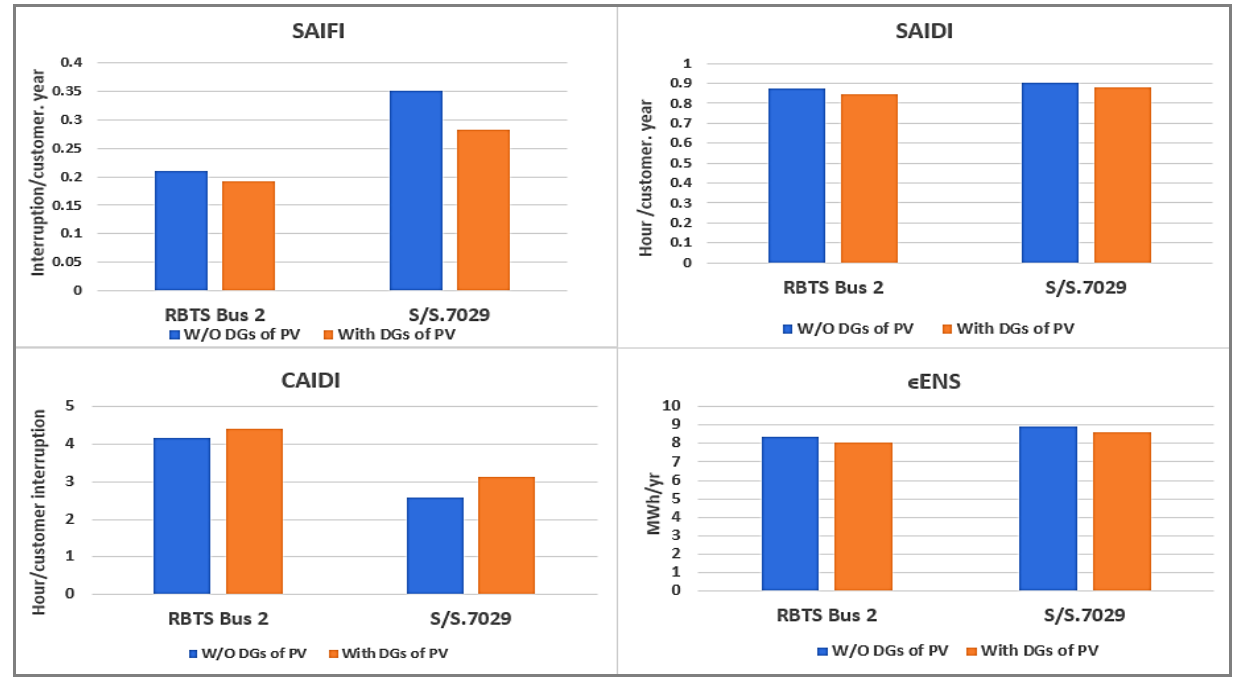

Figure 22. Comparison of system reliability indices for two distribution system networks.

\section{CONCLUSION}

The implementation of renewable resources in distribution networks is promising in many environment and economic aspects, such as reducing green gas emissions, reducing the power losses on distribution networks and improving reliability of power services. The distributed generators of PV could pave the way to integrate solar energy in distribution systems, which can deal with different modes of operation such as interconnected mode and islanded mode. The excess of PV generation does not lead to any negative impact on the system reliability, but they surely have significant economic impacts. Due to high correlation of PV output power during the peak hours of the load, the PV integration results in reduced net loads which leads to higher effective load carrying capability. In this study, the reliability evaluation was conducted on a test distribution network which is RBTS Bus 2. The data of RBTS Bus 2 have been used in this study because it offers a very detailed information for each distribution components (transformers, breakers, lines and busbars) such as the failure rate and average restoration time. The same study has been conducted on the original case of distribution network substation 7029 which is located at KSA Riyadh. Since the original RBTS Bus 2 and substation 7029 did not contain of any distributed generators, the two systems have been modified to include the PV's with different power output capacity. The probabilistic techniques used to evaluate the reliability of distribution networks containing PV as a distributed generator which is random in its output power 
Electrical Engineering: An International Journal (EEIJ) Vol.6, No.1/2, June 2019

production. MCS is a very useful tool, it requires only basic information to generate the artificial history of the distribution system components by generating large and random numbers of scenarios of the system element. The failure rates and average restoration times can be easily found by calculating the frequency and the duration of the down time of each load point in the system. The failures rates and average restoration times were assigned to all distributed generator resources, these indices were considered in reliability assessment studies. The common indices such as SAIFI, SAIDI, CAIDI and EENS have been calculated to evaluate the reliability of the distribution network in two cases without and with DGs of PV. The impact of the DGs of PV has been investigated and the simulation studies have shown that the implementation of DGs in the distribution system can improve the reliability of the system. In the RBTS containing DGs of PV SAIFI, SAIDI, CAIDI and $\in$ ENS were improved by $8.57 \% 3.23 \% 5.84 \% 4.29 \%$ respectively. In the Substation 7029 containing DGs of PV SAIFI, SAIDI, CAIDI and $\epsilon$ ENS were improved by $19.5 \% 2.25 \% 21.5 \% 3.9 \%$ respectively

\section{REFERENCES}

[1] Billinton, Roy, and Satish Jonnavithula. "A test system for teaching overall power system reliability assessment." IEEE Transactions on Power Systems, Volume: 11 (1996) 1670 - 1676.

[2] Rajkumar Viral, D.K. Khatod,“Optimal planning of distributed generation systems in distribution system:A review” Renewable and sustainable energy reviews 16(2012) 5146-5165.

[3] Energy Trend,PV Price Qut.[Online]. Available: http://pv.energytrend.com/pricequotes.

[4] International Energy Agency, Snapshot of Global Photovoltaic Markets, pp.1_16, 2016.

[5] N. M. Haegel, R. Margolis, T. Buonassisi, D. Feldman, A. Froitzheim, R. Garabedian,M. Green, S. Glunz, H.-M. Henning, B. Holder, I. Kaizuka, B. Kroposki, K. Matsubara,S. Niki, K. Sakurai, R. A. Schindler, W. Tumas, E. R. Weber, G. Wilson,M. Woodhouse, and S.Kurtz, _Terawatt-scale photovoltaics: Trajectories and challenges, Science, vol. 356, no. 6334, pp. 141_143, 2017.

[6] Renewable Energy Market Analysis: The GCC Region, International Renewable Energy Agency, 2016.

[7] Vision 2030, Kingdom of Saudi Arabia, April 2016.

[8] Internal estimate from U.S. Energy Information Administration http://www.eia.gov/beta/international/analysis_includes/countries_long/Saudi_Arabia/saudi_arabia.pd f.

[9] T. F. Wu, C. L. Shen, H. S. Nein, and G. F. Li, "A Single-Phase 3 W Inverter with Grid Connection and Active Power Filtering Based on Nonlinear Programming and Fast-zero-Phase Detection Algorithms", IEEE Transactions on Power Electronics, vol. 20, pp. 218-226, 2005.

[10] Wan \& Hamdan. "Modeling and Simulation Of Photovoltaic Module With MPPT", Conference: 2nd Annual International Conference on Sustainable Energy and Environmental Sciences volume 06 (SEES 2013).

[11] E.M. Natsheh, E.J. Blackhurs, A. Albarbar, PV System Monitoring and Performance Of A Grid Connected PV Power Station Located In Manchester-UK.

[12] L. Husshi , S. Jian, L. Sige, "Reliability evaluation of distribution system containing microgrid," China International Conference Electricity Distribution (CICED), China, September,2010,pp.1-6. 
Electrical Engineering: An International Journal (EEIJ) Vol.6, No.1/2, June 2019

[13] G. M. Masters, Renewable and Efficient Electric Power Systems, 2nd ed. New Jersey: Wiley-IEEE Press., 2004.

[14] S. Cha, D. Jeon, I. Lee, and J. Kim, "Reliability evaluation of distribution system connected photovoltaic generation considering weather effects," Probabilistic Methods Applied to Power Systems, International Conference, Ames, Iowa, USA, September 2004, pp. 451456.

[15] L. Husshi , S. Jian, L. Sige,"Reliability evaluation of distribution system containing microgrid," China International Conference Electricity Distribution (CICED),China,September, 2010,pp.1-6.

[16] SEC (2015) Electrical Data 2000-2013 [Online], Saudi Electricity Company. Available at https://www.se.com.sa/en-us/Pages/ElectricalData.aspx (accessed Feb 7, 2016).

[17] Javier Faulin • Angel A. Juan • Sebastián Martorell José-Emmanuel Ramírez-Márquez Hoang Pham, "Simulation Methods for Reliability and Availability of Complex Systems" Springer London Dordrecht Heidelberg New York (2010).

[18] R. Billinton and R. N. Allan, Reliability evaluation of power systems, Second edition. New York; published by Plenum Press, 1996.

[19] R. N. Allan, R. Billinton, I. Sjarief, L. Goel, and K.S. So, "A reliability test system for ducational purposes basic distribution system data and results," IEEE Transactions on Power Systems ,Vol. 6, No. 2, pp.813-820, May 1991.

\section{BIOGRAPHIES}

Abdulrahman K. AL-Sefri Received his B.S Degree in Electrical Engineering from King Khalid University in 2015. He is working as Senior Project Engineer at Schneider Electric Saudi Arabia for Solution and Services Ltd. His is currently pursuing his M.S degree at King Saud University. His research interests in reliability evaluation of power system involving renewable energy resources as distributed generators, power system operation and renewable energy resources.

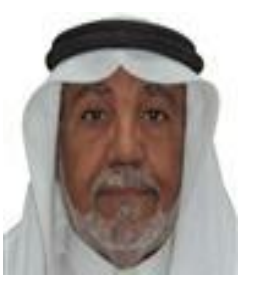

Abdullah M Al-ShaAlan joined the college of engineering, King University since receiving his doctorate in electrical engineering from the University of Manchester (UK) in 1985. His specialization and research interests fall within the areas of power system planning, reliability evaluation, electrical safety, environmental protection, load management and energy conservation. He participated in many local, regional and international technical and scientific committees, seminars, conferences and workshops. He offered consultancy services to many governmental and private

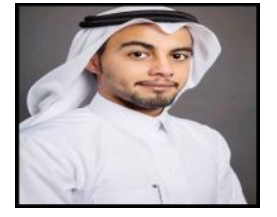
entities in his areas of specialization. He is an active member in many scientific societies and academic affiliations, including the IEEE as a life SM. He was one of the first founders of Cigrè (Gulf branch). He authored, co-authored and translated several books in various fields of electrical engineering as well as writing articles for public awareness in the safety of electrical installations and energy conservation. Obtained a lot of prizes, trophies and certificates of appreciations for his vast contributions and wide activities aimed at developing and improving the performance of several electricity sectors. Also, conducted many funded projects for local and foreign agencies. He is currently working as the supervisor of the "Zamil Industrial Group Chair for Electricity Conservation" at the College of Engineering, King Saud University, Riyadh, Kingdom of Saudi Arabia. Also working as a part-time consultant at the Saudi Arabian Standards Organization (SASO) since 1995 until the present time. 
Electrical Engineering: An International Journal (EEIJ) Vol.6, No.1/2, June 2019

\begin{abstract}
Abdul Hamid A.AlOhaly ObTained his PhD from the University of Missouri, Columbia, USA in 1984 then joined King Saud University as an assistant professor and associate professor in the Electrical Engineering Department. His interests are in the areas of analysis, dynamism, security and electrical system planning. He published more than 80 scientific papers in specialized engineering journals and proceedings of scientific conferences. He supervised many projects in various fields of electrical engineering. He also supervised and prepared many engineering researches and workshops in the field of electrical system planning and analysis, stability and security of electrical systems. He involved in many professional activities as a member of research teams to study many research projects funded by King Abdelaziz City for Science and Technology, the Saudi Electricity Company and the Research Center at King Saud University. He also served as a chairman of the technical committee for the electrical requirements of the Saudi Building Code. He also participated in all the annual meetings of the International Electrotechnical Commission (IEC). He also serves as a member of the Saudi Energy Efficiency Center (SEEC).
\end{abstract}

